\title{
The Relationship between National Culture and Succession Planning in Malaysian
} Public Universities

\author{
Abd Rahman Ahmad ${ }^{1 \star}$ \\ Nazia Keerio $^{2}$ (D) \\ Alaa S. Jameel ${ }^{3}$ (D) \\ Mohammed A. Karem ${ }^{4}$
}

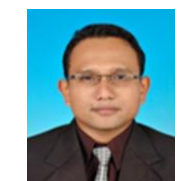

${ }_{1,2,3}$ Faculty of Technology Management and Business, Universiti Tun Hussein Onn Malaysia, Batu Pahat, Johor, Malaysia.

Malaysia.

Email: keerionazia@gmail.com

sEmail:salam.alaa2s@gmail.com

${ }^{4}$ Department of Public Administration, Cihan University-Erbil, Kurdistan Region, Iraq.

${ }^{4}$ Email: mohammad.abdulkarem@cihanuniversity.edu.iq

\begin{abstract}
This study investigates the role of national culture in succession planning. Higher education institutions ought to learn from corporate succession planning practices; nevertheless, succession planning principles must be adapted as needed to meet the unique needs of each institution. Studies of the influence of culture on succession planning in higher education institutions have not yet revealed the specific impact of national culture on succession planning. We use Hofstede's national culture dimensions, which are power distance, collectivism, masculinity, uncertainty avoidance and long-term orientation. Data were gathered from five universities in Malaysia, and were analyzed using structural equation modeling. Our findings show that the national culture of university employees influences succession planning. This study contributes to existing understanding of factors affecting succession planning, points towards further research, helps practitioners by demonstrating the importance of taking national culture into account and indicates the importance of implementing succession planning in public universities in Malaysia.
\end{abstract}

Keywords: Succession planning, National culture, Hofstede’s, Higher education institutions, Public universities.

Citation | Abd Rahman Ahmad; Nazia Keerio; Alaa S. Jameel; Mohammed A. Karem (2020). The Relationship between National Culture and Succession Planning in Malaysian Public Universities. Journal of Education and e-Learning Research, 7(3): 242-249.

History:
Received: 11 May 2020

Revised: 23 June 2020

Accepted: 27 July 2020

Published: 3 August 2020

Licensed: This work is licensed under a Creative Commons

Attribution 3.0 License (cc) $\mathrm{Er}$

Publisher: Asian Online Journal Publishing Group
Acknowledgement: All authors contributed to the conception and design of the study.

Funding: The authors would like to thank Research Management Office (RMC), Universiti Tun Hussein Onn Malaysia for allowing this paper to be presented by covering fees through UTHM research funds (E15501).

Competing Interests: The authors declare that they have no conflict of Competing

Transparency: The authors confirm that the manuscript is an honest, accurate, and transparent account of the study reported; that no vital features of the study have been omitted; and that any discrepancies from the study as planned have been explained.

Ethical: This study followed all ethical practices during writing.

\section{Contents}

1. Introduction

2. Literature Review 


\section{Contribution of this paper to the literature}

This research contributes to study on the effect of national culture on succession planning at Malaysian public universities. In other words, it explores the impact of national culture on succession planning, which, to the researchers' best knowledge, has somehow lacked scholarly attention.

\section{Introduction}

This study explores the role of national culture in institutions of higher education, which is a key factor influencing succession planning. This study addresses a challenge faced by leaders of every organization when implementing succession planning, which is to determine the factors that influence the performance of the organization. Organizational scholars have been involved in culture for the last three decades because they believe that organizational culture has an impact on succession planning (Lee \& Yu, 2004). However, it is generally recognized that culture works at various levels, and the organizational level is only one (Pizam, 1999). It is relevant for leaders to be aware of the effect of national culture when implementing succession planning. This study extends previous studies showing that organizational culture has an impact on succession planning (Lee \& $\mathrm{Yu}, 2004$ ) and that national culture has an impact on organizational culture. A wide range of political, historical, ideological, sociological, economic and psychological factors reflect the national culture (Park, Russell, \& Lee, 2007). Researchers have applied the impact of national culture on business behaviors to better understand cultural differences in conflict resolution, problem-solving, decision-making and management, and HR practices (Ahmad, 2019; Bankole-Minaflinou, 2019; Chua, Chrisman, \& Sharma, 2003; Culpan \& Kucukemiroglu, 1993; Dhaliwal \& Kangis, 2006; Koech \& Mwei, 2019). While there are various dimensions of national culture (Hampden-Turner \& Trompenaars, 1997; House et al., 1999) the current work adapts (Hofstede \& Usunier, 2003) to five cultural dimensions that have been used extensively to suggest an important link between culture and succession planning in organizations: collectivism, distance from power, masculinity, avoidance of uncertainty, and long-term orientation (Abdullah, Yusuff, \& Adam, 2013). For these reasons, we are investigating the effect of national culture in higher education institutions on succession planning. We argue that the national culture of employees of higher education institutions influences the implementation of succession planning and therefore indirectly affects university results.

\section{Literature Review}

Significant attention has been given to the impact of succession planning on organizational capacity or inability to implement strategies throughout the literature (Deshwal, 2015). According to the literature, succession planning refers directly to the growth and execution capacities of an organization, strategic priorities and initiatives (Hildebrand, 2015). Succession plans often affect organizations' long-term strategic viability because they help organizations to have the right people in place to meet stakeholders' goals and needs (Deshwal, 2015). As such, according to the literature, succession plans have the potential to have a significant impact on strategic capabilities (Adeyemi \& Adeyemi, 2019; Asiri, 2019; Deshwal, 2015; Hildebrand, 2015; Keerio \& Ahmad, 2019).

Succession plans are instrumental in fostering and ensuring alignment with different strategies (Hildebrand, 2015). Hildebrand (2015) explored the role succession plans play in aligning for-profit goals and activities consistently with business strategies. Succession plans have been described as a key component of strategic alignment (Hildebrand, 2015). Furthermore, for-profit organizations described consistent strategy execution and strategic alignment as a rationale for engaging in succession planning initiatives (Hildebrand, 2015). Anderson (2015) supported this concept, arguing that the departure of senior employees impedes meeting business goals.

Succession plans were described by Acree-Hamann (2016) and Stephens (2016) as a resource that organizations, following employee exits, use to be able to achieve objectives. According to Acree-Hamann (2016) organizations that lack sufficient succession plans are likely to have a dismal future. Stephens (2016) suggested vacancies in key positions resulted in the aforementioned dismal future, as suboptimal decisions and operations are often implemented during periods of key vacancies. According to Stephens (2016), when vacancies arise without developed succession plans, organizations can easily slip into a rushed crisis mode. Strategic planning, like succession planning, aids organizations in managing challenges and in executing correct plans and policies following the loss of key staff (Acree-Hamann, 2016).

Darvish and Temelie (2014) addressed succession planning and its relationship to institutional strategies. Higher education institutions experienced an increase in retirement, and succession planning was identified as an institutional stabilizing strategy (Darvish \& Temelie, 2014). Darvish and Temelie (2014) presented work indicating that succession planning would reduce the organizational and programmatic differences in key institutional roles associated with vacancies. Their work discussed the need for a formalized succession planning mechanism within organizations as a tool for fulfilling missions and objectives (Darvish \& Temelie, 2014). Institutions still follow an informal succession planning process which, according to Darvish and Temelie (2014) has resulted in inadequate and ineffective attempts to prepare successions.

Kumar and Kota (2017) presented potential succession planning benefits within higher education institutions through a case study on succession planning at universities. Succession strategies have been identified for creating incentives for professional growth and institutional stability during times of perceived instability (Kumar \& Kota, 2017). The authors demonstrated the importance of communicating succession plans to different stakeholders to avoid chaos and satisfy concerns regarding the institution's strategic direction (Kumar \& Kota, 2017). Smooth transitions are often linked to succession plans and help institutions avoid possible disruptions to student experience (Kumar \& Kota, 2017). Institutional stability and the consistency of institutional programs were preserved by succession planning efforts in the institutions researched by Kamil, Hashim, and Hamid (2016). Wallin, Cameron, and Sharples (2005) analyzed the succession planning programs at Daytona Community College and Guiford Technical Community College in an attempt to investigate the implications of succession planning in institutions of higher education. Wallin et al. (2005) presented evidence that the advantages associated with college succession planning included "the expected consistency of the organizational strategy, improved leadership efficiency, employer desirability, increased rates of employee satisfaction, and the ability to recruit and retain top 
talent." Although the primary focus of the analysis was not the effect of succession planning on policy, the work presented provided evidence supporting succession planning effects on institutional ability to retain continuity in the execution of different strategies. Wallin et al. (2005) indicated that organizations would not be able to provide the stability needed to manage operations and effectively execute strategies without succession planning being present. Succession plans have the potential to make it possible for institutions to step forward with different projects, policies and initiatives due to the continuity offered by succession plans.

Grossman (2014) researched succession planning within multiple higher education institutions in the Midwestern region. Research participants indicated that the importance of succession planning within their institutions has been accepted but implementation of actual succession planning programs and strategies has been sparse (Grossman, 2014). Grossman (2014) research participants seemed to agree that deficiencies in succession planning were harming institutions by creating gaps in leadership and barriers to sustainability and continuity. Vacancies created interruptions as perceived by the research participants, which harmed the institutions' ability to consistently implement strategies and programs (Grossman, 2014). Grossman (2014) suggested the possibility of greater implementation of succession plans if institutional stakeholders understood the strategic impact of succession planning in terms of sustainability and continuity.

\subsection{National Culture}

Every country's national culture is more powerful and stable than organizational culture, making it harder to change; national culture is not static, and can change over time (Hofstede, 1983). National culture has deep implications for variations in organizations' behaviors and performance (Kreiser, Marino, Dickson, \& Weaver, 2010). A wide range of political, historical, ideological, sociological, economic and psychological factors reflect the national culture (Park et al., 2007). Researchers have applied the impact of national culture on business behaviors to better understand cultural differences in conflict resolution, problem-solving, decision-making and management practices (Culpan \& Kucukemiroglu, 1993). National culture has many aspects (House et al., 1999).

The population of Malaysia is comprised of three ethnic groups: Malays, Chinese and Indians. The country's multi-ethnic makeup will have an impact on national culture. In 1971 the government released Malaysia's National Culture Policy to address this anxiety. The policy claimed that the national culture had to be based on the Malay indigenous culture, advising that Islam would be an important component in shaping national culture. FreyRidgway (1997) claimed that a great deal of national culture has to establish a "Malaysian-ness" that distinguishes Malaysians as a national community or class. In the context of the workplace, regardless of race, Malaysian employees display a high level of respect and deference to their superiors and accept status and hierarchy of power. Hofstede. and Bond (1988) find Malaysia high in the dimension of power distance. This suggests that Malaysian organizations prefer stability and predictability, and tend to value group preferences over individual decisionmaking. Hofstede's results are consistent with the element of equality-hierarchy proposed by Hampden-Turner and Trompenaars (1997). They identify Malaysia as a very hierarchically oriented society in which differences of status are understood and accepted, and in which power is concentrated in the hands of a few. In such societies, deference to superiors is very high, and the questioning of decisions made by those in positions of power is discouraged. Kennedy (2002) found that, overall, Malaysians placed a very high emphasis on the well-being of the collective and had a strong sense of respect for differences in hierarchy; they also asserted that the Malaysian culture did not foster assertive, confrontational behavior and that preserving harmony was of high priority.

If the above observations are applied to the research on succession by Kennedy (2002) and Hampden-Turner and Trompenaars (1997), it can be argued that Malaysian employees would not be likely to challenge succession decisions. Johnson, Kulesa, Cho, and Shavitt (2005) report conformity is stressed and submission is expected in high-power distance societies. There is little in the literature about the effect of culture in the Malaysian context on the reaction of employees to succession decisions. Based on countries with small power distances such as the United States or the United Kingdom, Johnson et al. (2005) say that decisions taken by subordinates are more likely to be questioned as power is disseminated to more citizens in those countries. Table 1 is a description of the three countries' cultural score calculation.

\begin{tabular}{l|c|c|c} 
Table 1 . Hofstede cultural score. \\
\hline Variables & Malaysia & United States & United Kingdom \\
\hline Individualism & 26 & 91 & 89 \\
\hline Power distance & 104 & 40 & 35 \\
\hline Uncertainty avoidance & 36 & 46 & 35 \\
\hline Masculinity vs. short-term & Not stated & 62 & 66 \\
\hline $\begin{array}{l}\text { Long-term } \\
\text { orientation }\end{array}$ & & Not stated \\
\hline \begin{tabular}{l} 
Source: Hofstede and Bond(1988),Cultural Dimensins. \\
\hline
\end{tabular}
\end{tabular}

In short, the five dimensions can be explained as follows: the first aspect, individualism, can be defined, not as an individual characteristic but as a social one, in contrast to its opposite, collectivism, which is the degree to which people are organized into groups within a society. On the individualistic side, we consider societies where the relations between individuals are loose; it is assumed that everyone should take care of himself or herself and his or her immediate family. On the collectivist side, we find societies where people are organized into large, unified ingroups from birth onwards, mostly extended families (with uncles, aunts and grandparents) who continue to defend them in return for unquestionable loyalty and condemn those outside of the group. Finally, for all communities in the world, the topic discussed by this aspect is an extremely fundamental one (Hofstede, 2011).

The second element, power distance, has been described as the degree to which the less powerful members of organizations and institutions (such as the family) agree and expect that power should be unequally distributed. This reflects inequality (more vs. less) but is defined from below rather than from above. A high degree of power distance can mean that the degree of injustice in a society is accepted as much by the citizens as by the leaders. 
Power and inequality are, of course, essential facts of any society. Although all societies are unequal, some are more unfair than others.

The third element is avoidance of uncertainty, which is not the same as avoidance of risk; it is about a society's tolerance of ambiguity. It indicates to what degree a community is training its participants to feel awkward or relaxed in unstructured circumstances. Situations that are unstructured are new, uncertain, shocking and different from normal. Uncertainty-avoiding cultures attempt to minimize the possibility of such situations through strict codes of conduct, laws and rules, disapproval of deviant opinions, and a belief in absolute Truth; 'there can be only one Truth and we have it.'

The fourth aspect is about masculinity and its opposite, femininity, again as a societal trait rather than an individual characteristic. This aspect refers to the distribution of values among the sexes, which is another fundamental problem for any society to which a number of solutions can be sought. The IBM studies revealed that (a) the values of women differ less among societies than the values of men; (b) the values of men from one country to another contain a dimension from very assertive and competitive and as distinct as possible from the values of women on the one hand, to modest and caring and similar to those of women on the other. The assertive pole was called 'masculine' and the modest, caring pole 'feminine.' Women in feminine countries have the same modest, caring values as men; they are somewhat assertive and competitive in male countries, but not as much as men, so these countries show a gap between the values of men and the values of women. This dimension is often a subject of taboo in male cultures (Hofstede, Neuijen, Ohayv, \& Sanders, 1990).

The fifth dimension was first identified using a questionnaire designed by Chinese scholars in a survey of students in 23 countries worldwide. Since all countries with a Confucian past ranked near one pole that could be correlated with hard work, the first author of the study, Michael Harris Bond, named this dimension the Confucian Work Dynamism Aspect. It turned out that this factor is closely associated with recent economic development. Since none of the four IBM dimensions were related to economic growth, I obtained permission from Bond to add his dimension to my four as a fifth (Hofstede \& Bond, 1988). Since it was found in a study comparing students from 23 nations, the majority of whom had never heard of Confucius, Hofstede renamed it Long-Term versus ShortTerm Orientation; the long-term pole corresponds to the Confucian Work Dynamism of Bond. Values found at this pole were perseverance, thrift, ordering relationships by status, and feeling shameful; values on the contrary, shortterm pole were reciprocal social obligations, respect for tradition, protecting one's 'face,' and personal steadfastness and stability. From around 500 BC the positively valued values of this element were already present in Confucius' teachings. There was much more in the teachings of Confucius, so Long-Term Orientation is not Confucianism per se, but is still present in Confucian heritage countries. Hofstede documents a low degree of Confucian dynamism in the United States but did not include the United Kingdom and Malaysia in his analysis (Hofstede \& Bond, 1988). In this study, the moderating effect on the relationships proposed in the previous sections between organizational culture and succession planning is expected from the national culture.

\section{Methodology}

The five dimensions of national culture that were used in this study (Hofstede, 1980) were derived from three broad factors on which the vast literature on national culture is based. The three main factors are (1) human relationship: distance from power, masculinity vs. femininity, individualism vs. collectivism; (2) nature relationship: avoidance of uncertainty; and (3) relationship with time: time orientation (past, present, and future). The aim of the study is to investigate the effect of national culture on succession planning implementation at Malaysia's public universities. There are limited studies in Malaysia on the relationship between national culture and succession planning, particularly in public universities (Kamil et al., 2016). The explanation for using quantitative methods is that previous succession planning studies were not generalizable due to the uniqueness of culture to other organizations (Fancher, 2007; Richards, 2009; Richards, 2016). Therefore, quantitative study is needed to generalize the study's findings.

As study respondents are public university academic staff in Malaysia, simple random sampling is appropriate where respondents are homogenous (Creswell, 2013). Academic staff in a university play an important role in achieving the aims of the university (Smyth, 2003), as the institutional culture is characterized by the diverse set of values and creeds of the institution's staff. Therefore, the academic staff is chosen to acquire information about the system of succession planning. Academic staff in the context of this research study meets the inclusion criteria based on the purpose of the study and the scope of the research questions. The simple random sampling technique was used to select those universities' academic staff.

The data were collected using the survey questionnaire. The survey was conducted online using a Google form. The Google form was sent to respondents via email. The questionnaire included forty-two questions on the dimensions of national culture (power distance, collectivism, masculinity, avoidance of ambiguity and long-term orientation) and succession planning. Members of the designated sample group were selected from the directory on the institution's website and sent an initial invitation email contact describing and inviting them to participate in the research study. Data coding and data screening were important tasks before carrying out statistical analysis since they aim to improve data accuracy by identifying missing data and outliers and fitting statistical assumptions such as normality and linearity. Data were screened before performing the study. Data were analyzed on the basis of research questions from the study. This research used simulation of the Structural Equation (SEM). The aim of this study is to examine the relationship between national culture and succession planning.

\section{Discussion and Results}

Uncertainty Avoidance (UA), Power Distance (PD), Masculinity (MAS), Long Term Orientation (LTO), and Collectivism (COL) are the dimensions of national culture included in this analysis. The UA construct was initially built on five objects, but objects UA2 and UA4 were dropped due to low loading factors. The PD construct was built on five items, the MAS construct was built on five items and the COL construct was initially built on five items, but elements COL2 and COL5 were excluded due to low loading factors. LTO was based on three items but was omitted from the analysis due to low loading factors of LTO2. The items were computed on a seven-point 
Likert scale ranging from "strongly disagree" to "strongly agree."

The model presented for the research measurement was validated using the PLS-SEM approach. Measuring conceptual or theoretical models for validation purposes in PLS-SEM involves a two-stage approach which begins with the evaluation of the measurement model (inner model) and is followed by the evaluation of the structural model (outer model). The aim of validating the model using this approach was to empirically gauge its success against established standards underpinning the validity of measurement and structural models.

\subsection{Assessment of Measurement Model}

This research's theoretical structure includes ten principal constructs. It shows that all the constructs are reflectively linked to zero-order constructs. The suggested method for evaluating a reflective latent variable model included evaluating the latent reflective variable to determine the validity of the design (Becker, Klein, \& Wetzels, 2012). Construct validity shows the extent to which the respective indicators represent the latent variables that underlie them. In addition, the indicators in the measurement model must meet the requirement for convergent and discriminant validity in order to create construct validity. Convergent validity tests the extent to which indicators of the same definition are associated, while discriminant validity measures a construct's degree of uniqueness in comparison to other constructs (Hair, Hult, Ringle, \& Sarstedt, 2016). The recommended practice for evaluating reflective measurement models is to assess the validity of the construct indicators in the model for each construct (Hair et al., 2016).

\subsection{Construct Validity Analysis}

The recommendation for evaluating convergent validity involves fulfilling the indicator reliability criteria by examining the indicator loadings, composite reliability and extracted average variance (AVE) and comparing the values with the recommended thresholds. The literature recommended values of 0.7 and above for both indicator loading and composite reliability, and 0.5 and above for AVE for a construct to achieve convergent validity (Hair et al., 2016). On the other hand, discriminant validity is tested by testing the cross loadings, the Fornell-Larcker criterion and the correlation ratio of heterotrait-monotrait (HTMT) (Hair et al., 2016). Table 2 shows the measurement model, indicating the factor loadings of the different indicators in the research model on the respective latent constructs.

\subsection{Convergent Validity}

As shown in Table 2, all loadings reach the recommended 0.7 threshold. The two collectivism items (COL2 and COL5) and the two ambiguity avoidance items (UA2 and UA4) have lower load than the required threshold value of 0.7 , so these objects must be removed. Due to low factor loading, the one item of long-term orientation and three items of succession planning must also be omitted. The remaining measures of each construct were strongly correlated with their respective construct.

\begin{tabular}{|c|c|c|c|c|c|c|}
\hline Variables & COL & LTO & MAS & PD & SP & $\mathbf{U A}$ \\
\hline $\mathrm{Col} 2$ & 0.767 & & & & & \\
\hline Col3 & 0.832 & & & & & \\
\hline Col4 & 0.913 & & & & & \\
\hline Col5 & 0.882 & & & & & \\
\hline $\mathrm{LTO} 2$ & & 0.912 & & & & \\
\hline LTO3 & & 0.752 & & & & \\
\hline Mas1 & & & 0.819 & & & \\
\hline Mas2 & & & 0.822 & & & \\
\hline Mas3 & & & 0.735 & & & \\
\hline Mas5 & & & 0.740 & & & \\
\hline PD1 & & & & 0.882 & & \\
\hline PD2 & & & & 0.858 & & \\
\hline PD3 & & & & 0.865 & & \\
\hline PD4 & & & & 0.736 & & \\
\hline PD5 & & & & 0.830 & & \\
\hline SP1 & & & & & 0.746 & \\
\hline SP10 & & & & & 0.759 & \\
\hline SP11 & & & & & 0.833 & \\
\hline SP14 & & & & & 0.633 & \\
\hline SP15 & & & & & 0.830 & \\
\hline SP17 & & & & & 0.759 & \\
\hline SP18 & & & & & 0.806 & \\
\hline SP19 & & & & & 0.828 & \\
\hline $\mathrm{SP} 2$ & & & & & 0.790 & \\
\hline SP3 & & & & & 0.773 & \\
\hline $\mathrm{SP} 5$ & & & & & 0.767 & \\
\hline SP6 & & & & & 0.775 & \\
\hline SP7 & & & & & 0.710 & \\
\hline SP8 & & & & & 0.856 & \\
\hline SP9 & & & & & 0.880 & \\
\hline UA2 & & & & & & 0.741 \\
\hline UA3 & & & & & & 0.757 \\
\hline UA4 & & & & & & 0.793 \\
\hline
\end{tabular}

To further verify the convergent validity of the measuring model, further analysis was conducted to determine 
the reliability of the composites and the AVEs of the latent constructs. Table 3 shows the constructs' composite reliability and AVEs within the study model. As indicated by the result, all reported composite reliability values, which measure the extent to which the indicators depict the latent construct, are higher than the recommended minimum threshold of 0.7. Likewise, all values reached the minimum threshold of 0.5 (Hair et al., 2016) that the recorded AVEs showed. Therefore, the convergent validity criterion was met.

Table 3. Measurement model.

\begin{tabular}{c|c|c}
\hline Variables & Composite Reliability & Average Variance Extracted (AVE) \\
\hline COL & 0.912 & 0.723 \\
\hline LTO & 0.821 & 0.699 \\
\hline MAS & 0.861 & 0.609 \\
\hline PD & 0.920 & 0.699 \\
\hline SP & 0.960 & 0.617 \\
\hline UA & 0.808 & 0.584 \\
\hline
\end{tabular}

\subsection{Discriminant Validity}

Table 3 demonstrates the outcome for the discriminant validity using the Fornell-Larcker criterion. Based on this criterion, discriminant validity is said to be achieved when the square root of the AVE of the value construct is greater than any association in the model between the construct and other constructs (Hair et al., 2016). As shown in Table 4, the diagonal values representing each construct's square root of the AVE are higher than the intercorrelations in the model between other constructs, thus meeting the criterion of discriminant validity.

\begin{tabular}{c|c|c|c|c|c|c}
\multicolumn{7}{c}{ Table 4. Fornell-Larcker criterion. } \\
\hline Variables & COL & LTO & MAS & PD & SP & UA \\
\hline COL & 0.850 & & & & & \\
\hline LTO & -0.256 & 0.836 & & & & \\
\hline MAS & 0.163 & -0.162 & 0.780 & & & \\
\hline PD & 0.378 & -0.271 & 0.254 & 0.836 & & \\
\hline SP & 0.690 & -0.257 & 0.346 & 0.552 & 0.785 & \\
\hline UA & 0.268 & -0.107 & 0.233 & 0.165 & 0.344 & 0.764 \\
\hline
\end{tabular}

Additionally, the heterotrait-monotrait (HTMT) approach was used to further check the attainment of discriminant validity. The HTMT approach is considered to be the most conservative and suitable criterion for assessing discriminant validity (Henseler, Ringle, \& Sarstedt, 2015). The decision rule for determining discriminant validity in the HTMT approach is less than $0.85(\mathrm{r}<$ HTMT0.85) for all inter-correlations between the construct of interest and the remaining constructs (Henseler et al., 2015). Table 5 shows the HTMT ratio result with respect to the research model constructs. All reported values were below the HTMT threshold of 0.85 and thus show the attainment of discriminant validity.

Table 5. Heterotrait-Monotrait (HTMT)

\begin{tabular}{c|c|c|c|c|c|c}
\hline Variables & COL & LTO & MAS & PD & SP & UA \\
\hline COL & & & & & & \\
\hline LTO & 0.351 & & & & & \\
\hline MAS & 0.196 & 0.258 & & & & \\
\hline PD & 0.423 & 0.362 & 0.294 & & & \\
\hline SP & 0.748 & 0.323 & 0.403 & 0.582 & & \\
\hline UA & 0.351 & 0.216 & 0.319 & 0.229 & 0.430 & \\
\hline
\end{tabular}

\subsection{Structural Equation Modeling}

It was shown in the previous section that all the recommended criteria for the validity of the measurement model were met and thus the first stage of the two-stage PLS-SEM evaluation process was achieved. The second stage of the cycle is discussed in this segment. The evaluation of the structural model involves collinearity assessment, structural model relationship significance checking, $\mathrm{R}^{2}$ level assessment, impact size assessment, and model predictive relevance assessment (Hair et al., 2016).

\subsection{Path Coefficients}

The path coefficients are estimates of the hypothesized relationship in the structural model between the endogenous latent construct (succession planning) and the exogenous latent constructs (power distance, collectivism, masculinity, uncertainty avoidance and long-term orientation). The magnitude and significance of the estimates indicate the strength of the relation. Path coefficients close to +1 are considered to represent strong positive relationships, while those closer to -1 are considered to represent strong negative relationships (Hair et al., 2016). The significance of the route estimates is calculated in the Smart PLS-SEM program through the bootstrapping procedure using the crucial t-value for meaning testing at a 5 -percent level of significance.

Table 6 shows the path coefficients $(\beta)$ with their respective t-values, $p$-values and $\mathrm{f}^{2}$ values. As shown in the table, four paths show significant positive relationships while only one path shows a significant negative relationship. The high significant positive path coefficient was between collectivism $(\beta=0.520, t=11.508, p<.000)$ and succession planning, while the least positive path coefficient was between uncertainty avoidance and succession planning $(\beta=0.118, \mathrm{t}=3.022, \mathrm{p}<.0 .003)$. Long-term orientation $(\beta=-0.006, \mathrm{t}=0.166, \mathrm{p}<.0 .868)$ showed no relationship with succession planning. The result suggests that implementation of succession planning is positively influenced by power distance, masculinity, collectivism and uncertainty avoidance. 
Table 6. Structural model.

\begin{tabular}{c|c|c|c|c|c|c}
\hline Variables & Std. beta & Std. error & T-statistic & P-value & F2 & R2 \\
\hline COL -> SP & 0.520 & 0.045 & 11.508 & 0.000 & 0.561 & \multirow{2}{*}{0.618} \\
\hline LTO -> SP & -0.006 & 0.037 & 0.166 & 0.868 & 0.000 & \\
\hline MAS -> SP & 0.158 & 0.036 & 4.367 & 0.000 & 0.058 & \\
\hline PD -> SP & 0.294 & 0.045 & 6.543 & 0.000 & 0.180 & \\
\hline UA -> SP & 0.118 & 0.039 & 3.022 & 0.003 & 0.033 & \\
\hline
\end{tabular}

\subsection{Coefficient of Determination $\left(R^{2}\right)$}

The determination coefficient $\left(\mathrm{R}^{2}\right)$ is the global measure of the predictive accuracy of a structural model. It is the indication of the combined effects of all the exogenous latent constructions on the model's endogenous structure. The $\mathrm{R}^{2}$ also represents the amount of variance on the latent endogenous structure explained by all the latent exogenous constructs in the structural model (Hair et al., 2016). The result shown in Table 6 indicated that in the structural model, the three exogenous constructs have a moderate effect on the latent endogenous construct $\left(\mathrm{R}^{2}=0.618\right)$. This shows that the combined effect of the latent exogenous constructs explains about 61 percent of the variance in the latent endogenous construct. This implies that power distance, masculinity, collectivism and uncertainty avoidance collectively forecast the role of national culture in implementing succession planning.

\subsection{Effect Size (f2)}

The R-square as an index for measuring overall output of the model can be further evaluated with regard to the contribution of the individual exogenous constructs that shaped the model. The f2 tests the change in $\mathrm{R} 2$ that caused a particular exogenous construct to be omitted in a model. It is used to measure the effect of exogenous individual constructs on the $\mathrm{R} 2$ value of the endogenous construct (Hair et al., 2016). The effect size is measured according to Cohen (2013) guidelines, in which $\mathrm{f}^{2}$ values of $.02, .15$ and .35 are considered as small, medium and large effects respectively. From Table 6 , the $\mathrm{f}^{2}$ values of the respective path relationships in the structural model are presented. The results indicate that collectivism and power distance have a large effect, with effect size of $\mathrm{f}^{2}$ $=0.561$ and $\mathrm{f}^{2}=0.180$, on succession planning. Meanwhile, masculinity and uncertainty avoidance have a slightly higher-than-medium effect on succession planning with effect sizes of $\mathrm{f}^{2}=0.033$ and $\mathrm{f}^{2}=0.058$. Finally, results showed that long-term orientation has no effect on succession planning.

\section{Discussion and Conclusion}

The effect of national culture on succession planning has been examined. The findings indicate that national culture greatly impacts succession planning implementation. The results of the data analysis for every hypothesis are discussed in detail in this section.

The findings of this study clearly indicate that national culture has an effect on succession planning in general, although the results showed substantial influence on succession planning by power distance, collectivism and masculinity. Due to the small number of items in the questionnaire, the negligible results of long-term orientation may be expected. However, it can be deduced in general that the national culture of employees and leaders has an influence on the choice of approach to succession planning implementation. The results of this study are consistent with a number of previous studies that focused on the association between national culture dimensions and succession planning (Menezes, Bhaskaran, \& Deswal, 2019; Ozdemir \& Harris, 2019; Peretz \& Parry, 2016). Further study shows that leadership and control roles enforce an organization's particular brand of corporate culture through the filter of local national culture. It shows that multinational corporations should take into account national values and customs which may limit their activities at their various corporate locations.

It has been stated that national cultures, whether in corporate organizations or in society, combine common views, values and norms relevant to a specific social structure. One point of view that can be applied here is that organizations are embedded in nations and organizational cultures and are shaped by the broader national culture in which organizations operate (Siakas, Georgiadou, \& Siakas, 2020). While there are several studies, as mentioned, that evaluate national culture and its impact on various factors such as organizational culture, what predominates in most cultural studies and the concept of succession planning is an undervaluation of national culture. The goal of this research was to assess the effect of national culture on succession planning. In other words, exploring the impact of national culture attention on succession planning, which, to the researcher's best knowledge, has somehow lacked scholarly attention, is a direct aim of this study. Therefore, based on these results, it can be concluded that, especially in the sense of this research, national culture can be regarded as a significant factor in the implementation of succession planning.

\section{References}

Abdullah, I. H. T., Yusuff, N. A., \& Adam, A. F. (2013). Family business succession: Hofstede's value dimension among Chinese in the East Coast of Malaysia. Journal of Basic and Applied Scientific Research, 3(11), 358-364.

Acree-Hamann, C. (2016). A call to action: Succession planning needed. Newborn and Infant Nursing Reviews, 16(3), 161-163.Available at: https://doi.org/10.1053/j.nainr.2016.07.001.

Adeyemi, B. A., \& Adeyemi, B. B. (2019). Integrating academic research activities in education into real life problem solving: The efficacy and barriers from lecturers' perspectives. American Journal of Education and Learning, 4(1), 29-35.Available at: 10.20448/804.4.1.29.35.

Ahmad, W. (2019). Causes of girls drop out from primary schools in Tehsil Bahrain District Swat, KPK Pakistan. Asian Journal of Contemporary Education, 3(1), 44-58.Available at: 10.18488/journal.137.2019.31.44.58

Anderson, J. (2015). Succession planning for impending retirements. Law Enforcement Management Institute, 1(1), 2-11.

Asiri, M. J. (2019). Do teachers' attitudes, perception of usefulness, and perceived social influences predict their behavioral intentions to use gamification in EFL classrooms? Evidence from the Middle East. International Journal of Education and Practice, 7(3), 112122.Available at: 10.18488/journal.61.2019.73.112.122.

Bankole-Minaflinou, E. (2019). Promoting critical thinking skills in EFL University students in Benin. International Journal of English Language and Literature Studies, 8(1), 1-13.Available at: 10.18488/journal.23.2019.81.1.13.

Becker, J.-M., Klein, K., \& Wetzels, M. (2012). Hierarchical latent variable models in PLS-SEM: Guidelines for using reflective-formative type models. Long Range Planning, 45(5-6), 359-394. 
Chua, J. H., Chrisman, J. J., \& Sharma, P. (2003). Succession and nonsuccession concerns of family firms and agency relationship with nonfamily managers. Family Business Review, 16(2), 89-107.Available at: https://doi.org/10.1111/j.1741-6248.2003.00089.x.

Cohen, J. (2013). Statistical power analysis for the behavioral sciences (2nd ed.). New York: Routledge.

Creswell, J. W. (2013). Research design: Qualitative, quantitative, and mixed methods approaches. Singapore: Sage Publications.

Culpan, R., \& Kucukemiroglu, O. (1993). A comparison of US and Japanese management styles and unit effectiveness. Management International Review, 33(1), 27-43

Darvish, H., \& Temelie, Z. N. (2014). A study on the relationship between succession planning and strategic planning. Case study: Payame Noor University of Aleshtar. Economic Insights-Trends \& Challenges, 66(1), 11-24.

Deshwal, P. (2015). Succession planning: The right people, for the right job, at the right time. International Journal of Advanced Research in Management and Social Sciences, 4(1 1), 57-67.

Dhaliwal, S., \& Kangis, P. (2006). Asians in the UK: Gender, generations and enterprise. Equal Opportunities International, 25(2), 92-108.

Fancher, L. P. (2007). The influence of organizational culture on the implementation of succession planning. Dissertation, Georgia State University.

Frey-Ridgway, S. (1997). The cultural dimension of international business. Collection Building, 16(1), 12-23.

Grossman, C. S. (2014). Succession planning and knowledge transfer in higher education. Dissertations/Theses - Doctoral Dissertations.

Hair, J. F. J., Hult, G. T. M., Ringle, C., \& Sarstedt, M. (2016). A primer on partial least squares structural equation modeling (Pls-Sem). USA: Sage Publications.

Hampden-Turner, C., \& Trompenaars, F. (1997). Response to geert hofstede. International Journal of Intercultural Relations, 21(1), 149159.Available at: https://doi.org/10.1016/s0147-1767(96)00042-9.

Henseler, J., Ringle, C. M., \& Sarstedt, M. (2015). A new criterion for assessing discriminant validity in variance-based structural equation modeling. Journal of the Academy of Marketing Science, 43(1), 115-135.

Hildebrand, U. (2015). Succession planning. In dos and don'ts in human resources management (pp. 81-84). Gabler, Berlin, Heidelberg: Springer.

Hofstede, G. (1980). Motivation, leadership, and organization: Do American theories apply abroad? Organizational Dynamics, 9(1), 4263.Available at: https://doi.org/10.1016/0090-2616(80)90013-3.

Hofstede, G. (1983). The cultural relativity of organizational practices and theories. Journal of International Business Studies, 14(2), 7589.Available at: https://doi.org/10.1057/palgrave.jibs.8490867.

Hofstede, G. (2011). Dimensionalizing cultures: The Hofstede model in context. Online Readings in Psychology and Culture, 2(1), 1-26.

Hofstede, G., \& Usunier, J.-C. (2003). Hofstede's dimensions of culture and their influence on international business negotiations. International Business Negotiation, 60(3), 137-153.

Hofstede, G., \& Bond, M. H. (1988). The Confucius connection: From cultural roots to economic growth. Organizational Dynamics, 16(4), 521.Available at: https://doi.org/10.1016/0090-2616(88)90009-5.

Hofstede, G., Neuijen, B., Ohayv, D. D., \& Sanders, G. (1990). Measuring organizational cultures: A qualitative and quantitative study across twenty cases. Administrative Science Quarterly, 35(2), 286-316.

House, R. J., Hanges, P. J., Ruiz-Quintanilla, S. A., Dorfman, P. W., Javidan, M., Dickson, M., \& Gupta, V. (1999). Cultural influences on leadership and organizations: Project GLOBE. Advances in Global Leadership, 1(2), 171-233.

Johnson, T., Kulesa, P., Cho, Y. I., \& Shavitt, S. (2005). The relation between culture and response styles: Evidence from 19 countries. Journal of Cross-Cultural Psychology, 36(2), 264-277.

Kamil, B. A. M., Hashim, J., \& Hamid, Z. A. (2016). Managing talents in higher education institutions: How effective the implementation of succession planning? Sains Humanika, 8(4-2), 67-72.

Keerio, N., \& Ahmad, A. R. (2019). The practices of succession planning in malaysian public universities. Paper presented at the Proceedings of the 33rd International Business Information Management Association Conference, IBIMA 2019: Education Excellence and Innovation Management through Vision 2020.

Kennedy, J. C. (2002). Leadership in Malaysia: Traditional values, international outlook. Academy of Management Perspectives, 16(3), 15-26.

Koech, H. C., \& Mwei, P. K. (2019). How secondary school mathematics teachers perceive the effectiveness of microteaching and teaching practice in their preservice education. Humanities and Social Sciences Letters, 7(1), 46-55.Available at: 10.18488/journal.73.2019.71.46.55.

Kreiser, P. M., Marino, L. D., Dickson, P., \& Weaver, K. M. (2010). Cultural influences on entrepreneurial orientation: The impact of national culture on risk taking and proactiveness in SMEs. Entrepreneurship Theory and Practice, 34(5), 959-984.Available at: https://doi.org/10.1111/j.1540-6520.2010.00396.x.

Kumar, A. V., \& Kota, S. (2017). Succession planning-a success story-a case study of skyline university college. Perspectiva: A Case Research Journal, 3(1), 63-69.

Lee, S. K. J., \& Yu, K. (2004). Corporate culture and organizational performance. Journal of Managerial Psychology, $19(4), 340-359$.

Menezes, K. A., Bhaskaran, S., \& Deswal, A. (2019). Effects of national culture on leadership succession planning in small-to-medium scale family enterprises. International Journal of Entrepreneurship and Small Business, 38(1-2), 210-231.

Ozdemir, O., \& Harris, P. (2019). Primogeniture in Turkish family owned businesses: An examination of daughter succession, the impact of national culture on Gendered Norms and leadership challenge. International Journal of Family Business and Management, 3(1), 1-18.

Park, H., Russell, C., \& Lee, J. (2007). National culture and environmental sustainability: A cross-national analysis. Journal of Economics and Finance, 31(1), 104-121.Available at: https://doi.org/10.1007/bfo2751516.

Peretz, H., \& Parry, E. (2016). Impact of national culture on the use and outcomes of E-Hrm. Paper presented at the Paper presented at the Academy of Management Proceedings.

Pizam, A. (1999). Cross-cultural tourist behavior. Consumer Behavior in Travel and Tourism, 13(1), 393-411.

Richards, C. L. (2009). A new paradigm: Strategies for succession planning in higher education: Citeseer. Dissertations/Theses - Doctoral Dissertations.

Richards., R. C. (2016). Succession planning in higher education: The influence of culture on the succession process in a community college. Unpublished Doctoral Dissertation, Tift College of Education, Mercer University.

Siakas, K., Georgiadou, E., \& Siakas, D. (2020). The influence of national and organisational culture on knowledge sharing in distributed teams Information Diffusion Management and Knowledge Sharing: Breakthroughs in Research and Practice (pp. 533-555): IGI Global.

Smyth, R. (2003). Concepts of change: Enhancing the practice of academic staff development in higher education. International Journal for Academic Development, 1-2(1-2), 51-60.Available at: 1080/1360144042000277937.

Stephens, S. (2016). Succession planning: Don't get caught off guard: Planning for staff transitions. Biomedical Instrumentation $\mathcal{F}^{2}$ Technology, $50(6), 451-453$.

Wallin, D., Cameron, D. W., \& Sharples, K. (2005). Succession planning and targeted leadership development. Community College Journal, 76(1), 24-28. 